—Published in: D. Machuca (ed.) Moral Skepticism. New York: Routledge (2018): 49-70—

This is the penultimate draft. For the definitive text, please consult the published version:

bttps:// wown.taylorfrancis.com/ books/e/9781315627861/chapters/10.4324/9781315627861-3

\title{
Error-Theory, Relaxation and Inferentialism
}

Christine Tiefensee

\begin{abstract}
This contribution considers whether or not it is possible to devise a coherent form of external skepticism about the normative if we 'relax' about normative ontology by regarding claims about the existence of normative truths and properties themselves as normative. I answer this question in the positive: A coherent form of non-normative error-theories can be developed even against a relaxed background. However, this form no longer makes any reference to the alleged falsity of normative judgments, nor the non-existence of normative properties. Instead, it concerns a specifically inferentialist construal of error-theories which suggests that error-theorists should abstain from any claims about normative ontology to focus exclusively on claims about the inferential role of normative vocabulary. As I will show, this suggestion affords a number of important advantages. However, it also comes at a cost, in that it might not only change the letter, but also the spirit of traditional errortheories.
\end{abstract}

\section{Introduction}

Is it possible to devise a coherent form of external skepticism about the moral? Traditionally, there has been little doubt that we should answer this question in the affirmative. After all, when declaring that all moral judgments are false because there are no moral properties, error-theorists have repeatedly stressed that they are putting forward a thesis about the moral domain, not one within it: they are, to use Mackie's (1977: 15) famous formulation, making a metaphysical claim about the "fabric of the world". However, this understanding has lately come under pressure from various directions. Ronald Dworkin $(1996,2011)$ was one of the first to challenge the possibility of defending external skepticism about the moral, arguing that all skeptical stances about the existence of moral properties presuppose the truth of some positive moral judgment and must thus be understood as varieties of internal skepticism. Minimalist conceptions of truth, fact and property, which have recently stirred much debate in the wake of Jamie Dreier's (2004) problem of creeping minimalism, appear to suggest a similar conclusion by entailing that there is no substantive difference between asserting a moral claim, such as 'Stealing is wrong', and ascribing truth to this claim by asserting 'It is true that stealing is wrong'. At the same time, so-called 'relaxed' moral realists such as Tim Scanlon (2014) stress that, contrary to philosophical lore, their claims about moral ontology must not be read as robustly metaphysical theses, but as moral commitments that are to be assessed on grounds of domain-internal, moral standards. But if relaxed moral realists' endorsement of moral truths' existence is now to be interpreted as a moral position, then surely error-theorists' rejection of these very truths must be just as moral. If sound, this relaxed, non-metaphysical reading of moral ontology would spell serious 
trouble for error-theories: were their claim that there are no moral truths itself moral, error-theories would not merely lose their robustly metaphysical status, but would be outright incoherent.

Although I will present considerations that aim to bestow some plausibility on these recent developments towards relaxed, non-metaphysical readings of moral truth claims, my primary concern here will not be whether or not we should indeed relax about moral ontology. Rather, I will investigate if, and if so how, a coherent, non-moral reading of error-theories could be available even if it were agreed that claims about the (non-)existence of moral properties are indeed moral. After all, much has been written on how minimalism's non-metaphysical take on truth, fact and property may affect the debate between moral realists and expressivists; far less thought has been devoted to its implications for our understanding of error-theories.

In this contribution, I seek to address this imbalance. To lay my cards on the table, though, I do so even though I am not an error-theorist myself. Yet, whilst I believe that error-theories should be rejected, I also believe that it is of general interest whether or not external skepticism about the moral is at all possible. I will answer this question in the positive: a coherent form of external error-theories can indeed be devised. However, this form no longer makes any reference to the alleged falsity of moral judgments and the non-existence of moral properties. Instead, it concerns a specifically inferentialist construal which suggests that error-theorists should abstain from any claims about moral ontology and focus exclusively on claims about the inferential role of moral vocabulary. Consequently, whereas error-theories have traditionally been taken to consist of a conceptual component, stating that moral discourse is centrally committed to some thesis $T$, and an ontological component, showing this thesis $T$ to be false (Joyce 2001: 5), this inferentialist construal will comprise only the conceptual element and abandon all ontological claims.

As I will show, this suggestion affords a number of important advantages. However, it also comes at a cost, in that it might change not only the letter, but also the spirit of traditional error-theories. As such, this paper can be understood as offering error-theorists a suggestion as to how the non-moral, external status of their position might be saved. Whether or not this proposal is one that error-theorists would want to accept, remains for them to decide.

The next section seeks to motivate a relaxed, non-metaphysical reading of moral ontology. As hinted above, the considerations presented will not construct a conclusive case for this relaxed stance, but are merely intended to provide sufficient grounds for making this moral reading plausible. ${ }^{1}$ Based on an error-theoretic counterargument to this relaxed interpretation, Section 3 will lay the foundations for developing a form of skepticism which qualifies as external even if we relax about moral ontology. Section 4 will spell out this inferentialist conception of error-theories in greater detail. Section 5 will conclude by considering what error-theorists might gain, but also what they may lose, by adopting this modified understanding of their position.

For convenience's sake, I will help myself to some stipulated terminology. The term 'ontological' will be applied to theses about the existence and nature of truths, facts and properties. As such, 'moral ontology' will comprise claims about the existence and nature of moral truths, facts and properties. 'Metaphysical', in turn, will be used more narrowly, in that I will reserve it for views that hold the truth of claims about

\footnotetext{
${ }^{1}$ Given this focus on relaxed moral realism, I will not consider how error-theorists could or would seek to refute non-relaxed, metaphysical versions of moral realism.
} 
moral ontology to be grounded on non-moral, metaphysical considerations. Metaphysical considerations will be understood as presupposing that there is a domain-neutral understanding for the concept of 'existence' as well as general existence conditions which apply equally across all domains. The relaxed position will then be taken to deny that such domain-neutral senses and criteria of existence are tenable. This paper thus presupposes a Carnapian distinction between internal questions that are asked within a framework or domain, and external questions that are posed about this domain, ${ }^{2}$ where moral considerations count as domain-internal and metaphysical considerations as domain-external.

Despite the dislike that many of them share about this term, those advocating a moral, non-metaphysical reading of moral ontology will be called 'relaxed philosophers'. Amongst this relaxed camp, we can find a variety of different philosophers who, despite their agreement on moral interpretations of moral ontology, somewhat surprisingly differ not only on how and why to relax about moral truths, but also on most other philosophical questions. ${ }^{3}$ Although I will follow Scanlon's (2014) account most closely, my interpretation of relaxed realism will borrow from all these different approaches without suggesting that every relaxed philosopher will agree with everything I have to say on moral readings of moral ontology. Finally, in line with the specific focus of this volume on moral skepticism, I will understand error-theories locally, i.e. as encompassing the moral domain but not normative discourse more widely. ${ }^{4}$ Arguably, the difference between moral and normative error-theories impacts on how far-reaching relaxed critiques of error-theories are. Whenever it does so it will be indicated in the text.

\section{Relaxing about Moral Ontology}

Assume, then, that you hear philosophers asserting claims such as "There are no moral properties," "Moral facts are sui generis," or "Moral properties are mind-independent." What kinds of claims are those philosophers propounding when defending these theses? According to one very plausible reading, they are putting forward metaphysical claims, which assess the ontological foundation of the moral from a standpoint outside of the moral domain. Given this very intuitive categorization, why believe that claims about moral ontology are not metaphysical, but moral? Put differently, why leave metaphysics behind and relax about moral ontology?

Relaxation is triggered by a diverse array of impulses—-such as Hume's Law, interpretations of metaethical theses, or minimalism about truth, fact and property-, and all may have their role to play when rejecting metaphysical approaches to moral ontology. Its main driver, though, concerns the way in which we are supposed to approach the very basic ontological question "What exists?". Following our philosophical training or, maybe more charitably, our intuitive inclination, we may feel disposed to tackle this question by searching for some general criterion of existence which applies across all

\footnotetext{
${ }^{2}$ Yet, it does so without endorsing Carnap's (1950) own take on such an internal/external distinction.

3 These include Thomas Nagel (1986), Ronald Dworkin (1996, 2011), Simon Blackburn (1998), Matthew Kramer (2009), Derek Parfit (2011), and Thomas Scanlon (2014).

${ }^{4}$ I do so despite generally agreeing with Streumer (forthcoming), and thus disagreeing with Mackie (1977), Joyce (2001), and Olson (2014), that error-theories cannot be understood as being confined to the moral domain only.
} 
domains and settles whether or not a thing exists irrespective of the subject area in question. For instance, assume that this criterion proclaimed that existence is conditioned on causal efficacy. If so, do genes exist? Yes, they do, because genes causally impact on how we look and how likely it is for us to contract cancer, say. Do numbers exist? No, they do not, because numbers are not causally efficacious. Or imagine that existence were tied to explanatory indispensability. If so, are there electrons? Yes, there are, because electrons are explanatorily indispensable. Are there moral properties? No, there are not, because we can do without them in our best explanations (or so many philosophers argue). According to relaxed philosophers, despite such potential philosophical inclinations to the contrary, this general, domain-neutral approach to existence questions is fundamentally misguided: there are no general, substantive conditions of existence that would apply across all subject domains. Instead, existence questions can only ever be answered on grounds of the domain-internal standards that govern the respective subject matter. In order to justify the claim that electrons exist, say, the requirements of science will demand that electrons are causally and explanatorily efficacious. When determining whether or not there exists a Baroque age, though, we must not consult science, but need to draw on aesthetic theories, whereas it is moral considerations on grounds of which we must answer questions about the existence of virtue, say. As Scanlon (2014: 25) puts it, we "make claims expressed by the existential quantifier in many domains, but what is required to justify any existential claim, and what follows from such a claim, varies, depending on the kind of thing that is claimed to exist." Furthermore, since the notion of existence is closely related to those of truth and fact, we can add that just as existence questions do not require domain-neutral, metaphysical enquiries, nor do questions of truth and fact: no matter whether we ask if an even prime number exists, or if it is true that there is some prime number which is even, or if it is a mathematical fact that there is an even prime number, we are thrown back to the mathematical question of whether or not some prime number is even. ${ }^{5}$ At no stage do metaphysical thoughts enter into these considerations.

Importantly, relaxing about ontology does not entail that there are no important ontological questions to be addressed. It does entail, though, that these questions are domain-specific, and as such can be answered neither on domain-neutral grounds, nor on the basis of the standards of some other domain. ${ }^{6}$ Just as importantly, once these

5 This obviously presupposes minimalist notions of truth and fact, according to which facts are no more than true propositions, where the proposition that $p$ is true iff $p$. Compare also Blackburn's (1998: 78) appeal to Ramsey's ladder: "Because of ... minimalism we can have for free what look $[\mathrm{s}]$ like a ladder of philosophical ascent: ' $p$ ', 'it is true that $p$ ', 'it is really and truly a fact that $p$ ' ..., for none of these terms, in Ramsey's view, marks an addition to the original judgement." Some metaethicists have argued that although there are such minimalist notions of truth, fact, property and existence, these are neither the only possible understandings of these concepts, nor legitimate interpretations as far as ontological matters are concerned (cf. Horgan/Timmons 2015).

6 This leaves out a key qualification that Scanlon (2014: 19) proposes: namely, that some $D$ proposition $p$ is true iff $D$-specific standards entail $p$ 's truth and $p$ does not conflict with some other domain $E$. This 'no-conflict clause' is important, as it does allow for the relevance of domain-external standards for $p$ 's truth if domain $E$ has jurisdiction over $p$ 's presuppositions. As such, a relaxed realist such as Scanlon does not just argue that the truth of moral claims is settled by moral standards, but also that (pure) moral claims, such as "Promoting happiness is good," have no problematic presuppositions within any other domain. This is why, as I explain below, ontological and epistemological queerness arguments are counted as misguided if they mistakenly assume that moral discourse does possess such presuppositions which would make 
domain-specific standards entail that virtue exists, or that claims about oceans and numbers are true, there is no further question as to whether virtue, oceans and numbers really exist and whether claims about them are really true. The very general existential question "What exists?," then, is parasitic on specific, domain-internal existential questions such as "Are there numbers?," "Are there tables?," or "Are there reasons?": we can answer the former only on grounds of answering the latter. Without the latter, we have no grip on the former.

Let us return to moral ontology, then, and consider a claim such as "It is a fact that happiness is good." As has just been mentioned, this claim could just as easily be expressed by using the formulations "It is true that happiness is good," "Happiness possesses the moral property of goodness," or simply "Happiness is good": given nonmetaphysical notions of truth, fact and property, we can slide seamlessly between these four claims without adding or subtracting any metaphysical content. How do we find out whether or not we are justified in committing ourselves to the goodness of happiness? The way not to proceed is to start asking questions about the metaphysical nature of the property that is ascribed to happiness. That is, we should not declare that we would be justified in believing in the existence of goodness only if this seemingly 'queer' property featured in our best causal explanations or could be placed within a natural world, or if there were some metaphysical relation 'in the world', as it is often put, that would make it true or explain the goodness of happiness. Doing so would amount to imposing illegitimately the standards of the natural domain to the moral domain, and thus misunderstand what it takes for moral ontological commitment to be justified. What we need to do instead is to engage in moral enquiry and consult our moral theories to find out whether or not happiness is indeed good. Importantly, if these moral considerations show that happiness is good, this settles that we are justified in committing ourselves to the goodness of happiness; ${ }^{7}$ to ask for further, metaphysical support for this ontological commitment would be to misconstrue what is required to justify claims such as "Goodness exists" or "Happiness has the property of goodness."

Hence, if relaxed philosophers are right, metaphysically driven error-theories are mistaken: justification of moral ontological commitment does not depend on domainexternal, metaphysical considerations. Error-theorists' skepticism is, therefore, either misguided if understood as an external position assessing moral ontological commitment on grounds of domain-external, metaphysical standards, or must be re-interpreted as a form of internal skepticism that operates from within the moral domain. Either way, relaxing about moral ontology leaves external readings of error-theories in an awkward dilemma: its first horn pulls the rug from under error-theoretic attempts to

moral properties queer. Without arguing this point here, this 'no-conflict clause' helps relaxed realists to deal with objections of ontological proliferation, e.g. with regard to the existence of witches or magical elves. But it also caters for local error-theories, such as those rejecting moral but not normative truths: in this case, it is the normative domain which supposedly shows that the presuppositions of the moral domain are false (cf. n. 7 and 8). In this context, Joyce's (2001: 45-49) remarks on Carnap are particularly interesting, as they appear to accept that external skepticism about the moral domain presupposes the conceptual and normative framework of the domain of practical rationality.

7 At this point a caveat is in order: For, it might be argued that even the truth of a claim such as "Happiness is good" is not settled by moral considerations alone, as it also has the normative presupposition that there are reasons which speak for happiness in a way that is required for this claim to be true, i.e. objective, categorical or irreducibly normative reasons. I return to this thought in n. 8 . 
reject moral truths, facts and properties on grounds of alleged metaphysical 'queerness' by showing that such metaphysical considerations do not apply to moral discourse; the second presupposes the truth of some moral consideration and thus renders them incoherent. ${ }^{8}$

Now, I appreciate that these previous paragraphs present relaxed views on existence, truth and fact, but do not argue for them. As such, they will hardly convince those philosophers who have already taken the firm stance that this relaxed approach must be rejected. However, as providing further arguments for relaxation would require us to involve ourselves in metaontological debate and thus take us too far afield, let me follow Amie Thomasson (2007: 5) in appealing to those who are still somewhat neutral and open-minded about these questions. That is, let me ask the admittedly leading question: if you are inclined to endorse statements such as "It is wrong to read others" diaries," or "I ought to spend more time with my grannie," and if you believe that the correct moral standards support claims such as these, what more would you possibly require also to endorse the ontological statements that there is the property of wrongness, or that this obligation exists? If, as I hope that you would do, you answer "Nothing," you take a relaxed stance on moral ontology.

\section{Morality, Negations and the Opening of a Different Avenue}

However, an important objection to this relaxed project will most certainly have entered error-theorists' mind by now. This relies on a move which has gained so much support amongst error-theorists in recent years that it cannot be ignored here. ${ }^{9}$ Interestingly, advocates of this move agree with relaxed philosophers that statements endorsing the existence of moral truths and facts are themselves moral; they might even agree that moral realism, proclaiming the existence of such moral truths and properties, is itself a moral position. At the same time, they contradict relaxed philosophers by declaring that denying the existence of moral truths and facts is not moral, just as the statement "Moral realism is false" does not express a moral judgment (Streumer forthcoming: ch. 8). This arguably rather surprising move is built on two key components. The first disputes that moral discourse is closed under negation. That is, although the claim

(M) Making others unhappy is wrong

\footnotetext{
8 In n. 7, I have indicated that the truth of a claim such as "Happiness is good" arguably has the normative presupposition that there are objective reasons. This, in turn, allows local errortheorists such as Mackie (1977), Joyce (2001) and Olson (2014) to submit that this moral claim is false because its normative presupposition is false: There are no such reasons. If tenable, this would indeed be a form of external, albeit normative, skepticism that even relaxed philosophers would recognize as such. However, they would reject this form of external skepticism as soon as it is based on the metaphysical objection that such objective reasons would be "metaphysically mysterious" (Olson 2014: 136). Accordingly, although error-theories which encompass the moral but not the normative could qualify as a form of external skepticism about the moral, the way in which they are generally developed also mistakenly assumes that moral claims have false metaphysical presuppositions, and thus succumb to the first horn. Still, the dilemma presented here admittedly is stronger in the case of normative error-theories than in that of local, moral error-theories.

9 In somewhat different versions, it can be found in Pigden (2007), Olson (2014), and Streumer (forthcoming).
} 
is moral-just as the corresponding claims " $(\mathrm{M})$ is true," " $(\mathrm{M})$ states a moral fact" or "Generating unhappiness possesses the moral property of wrongness" are moral-its negation

$(\neg \mathrm{M})$ Making others unhappy is not wrong,

together with the corresponding claims that $(\mathrm{M})$ is false, or that there is no moral fact that making others unhappy is wrong, or that generating unhappiness does not possess the property of wrongness, are not moral.

Its second component provides the explanation of why $(\neg \mathrm{M})$ is not moral: for a claim to qualify as such, it must conceptually entail that something satisfies a moral predicate (Streumer forthcoming) or, put differently, that some moral property is ascribed to some object of evaluation. Of course, (M) satisfies this requirement and is, therefore, moral; however, negations such as $(\neg \mathrm{M})$ do not. And since error-theorists' core thesis just is that there are no moral truths or properties, and thus that no moral predicate is ever satisfied, we can conclude that contrary to relaxed philosophers' claim, error-theories are not moral even if moral realism and the endorsement of moral properties' existence were indeed moral. ${ }^{10}$

As it stands, I do not believe that this error-theoretic move succeeds. However, it might still point error-theorists in the right direction. Before coming to these positive implications, though, let us start with the negative part and ask why this retort is not strong enough to refute relaxed philosophers. One way to show as much would be to question the claim that $(\neg \mathrm{M})$ does not conceptually entail that some moral predicate is satisfied. After all, does $(\neg \mathrm{M})$ not conceptually imply that making others unhappy is permissible, and thus that there is at least one moral property which is indeed instantiated? Error-theorists have recently started to block this train of thought by arguing that whilst 'not wrong' conversationally implicates 'permissible', no conceptual entailment relations hold between these predicates. If so, $(\neg \mathrm{M})$ would implicate, but not conceptually entail that the predicate 'permissible' is satisfied, and would thus retain its non-moral classification.

Although I find this appeal to conversational implicatures problematic, I will not join the controversy about conceptual entailments between 'not wrong' and 'permissible' here. Instead, let me hint at a second way to attack this error-theoretic move, which questions that in order for some claim to qualify as moral, it must entail satisfaction of a moral predicate or ascription of some moral property. To motivate these qualms, take the statement

(U) $X$ is impermissible iff $X$ generates less utility than some alternative $Y$.

I assume that many - although certainly not all—would agree that $(\mathrm{U})$ is at least very naturally read as a moral claim. Yet, (U) itself does not ascribe a moral property, nor

\footnotetext{
${ }^{10}$ Note that if successful, this move would render it unnecessary to limit error-theories' thesis to positive moral claims only, as for instance suggested by Sinnott-Armstrong (2006). That is, error-theorists could keep proclaiming that all moral claims are false without risking incoherence, as it would be fully consistent to endorse the truth of the non-moral claim ( $\neg \mathrm{M})$ whilst proclaiming the falsity of the moral claim (M). This is a significant advantage over interpretations which understand error-theoretic theses as being limited to positive moral claims only, as there is, I believe, no principled way to distinguish between positive and negative moral statements.
} 
conceptually entail that some moral predicate is satisfied. Consequently, it does not qualify as moral on the error-theorist's count. Or consider the example

$(\neg \mathrm{E}) \quad$ Phlogiston does not exist.

Again, I presume that many would agree that $(\neg \mathrm{E})$ is an empirical claim. Assuming, though, that the error-theorist's categorization criterion applies tout court, in that for some statement to count as $D$, it must conceptually entail that some $D$-predicate is satisfied, $(\neg \mathrm{E})$ would fail to qualify as empirical as it does not ascribe an empirical property, nor conceptually entail that some other empirical predicate is satisfied. Of course, error-theorists might be willing to accept these categorizations of $(\mathrm{U})$ and $(\neg \mathrm{E})$ as not moral and not empirical respectively. ${ }^{11}$ However, given their counter-intuitive flavor, they would do so at some theoretical cost.

Assume, then, that we wanted to classify $(\neg \mathrm{E})$ as empirical although it does not ascribe any empirical property. Since the error-theorists' preferred categorization criterion cannot help us in this respect, it is clear that we must replace it with some other criterion. Here is one such alternative: $(\neg \mathrm{E})$ is empirical because its truth is determined by empirical methods and scientific standards. That is, $(\neg \mathrm{E})$ has empirical status because it is based on considerations such as the following: Its truth must be examined on grounds of observations and experiments; this includes appeal to scientific theories; for our belief in phlogiston's existence to be justified, phlogiston would have to be explanatorily indispensable and causally efficacious; $(\neg \mathrm{E})$ can conflict with other empirical claims, and so on. Put differently, $(\neg \mathrm{E})$ is very plausibly categorized as empirical because it is based on and governed by scientific norms. Could we apply the same thoughts to $(\mathrm{U})$ ? Arguably yes: $(\mathrm{U})$ is so naturally understood as moral because its truth must be examined by moral reasoning about the link between impermissibility and utility maximization, because $(\mathrm{U})$ can explain why certain actions would not be justified, because it has the ability to guide our deliberation about what to do, because it concerns our actions towards others, because it cannot be confirmed by observation and experiments, because $(\mathrm{U})$ might follow from or have implications for other moral claims, and so on. Arguably, then, $(\mathrm{U})$ is very naturally characterized as moral because it is based on and governed by moral norms. ${ }^{12}$

What about $(\neg \mathrm{M})$ ? On the one hand, the same considerations apply: Contrary to error-theorists' claim, $(\neg \mathrm{M})$ is very plausibly sorted into moral discourse because it is naturally understood as the conclusion of moral reflections, even if it does not entail satisfaction of some moral predicate. On the other hand, we should not forget that language can be used very flexibly, so that we certainly ought to beware of believing that negations such as $(\neg \mathrm{M})$ can only ever be understood as first-order, moral claims. As Plunkett and Sundell (2013) convincingly argue, claims such as (M) and ( $\neg \mathrm{M})$ could, for instance, also be used metalinguistically, e.g., as making claims about how moral concepts ought to be used, what their presuppositions are, to which objects they can mean-

11 If, in turn, they wanted to categorize $(\neg \mathrm{E})$ as empirical but $(\neg \mathrm{U})$ and $(\neg \mathrm{M})$ as non-moral, they would have to introduce different categorization criteria for different domains, only some of which prescribed satisfaction of some D-predicate. How plausible this move would be cannot be considered here.

12 How do we know which standards are moral and, more generally, what characterizes the moral domain? This is a very difficult question which relaxed realists cannot shirk from addressing. However, as it would take us too far afield, I will, admittedly disappointingly, continue to rely on an intuitive understanding of the moral domain here. 
ingfully applied, etc. That is, when declaring that a flower's turning towards the light is not virtuous, it would be rather uncharitable of me to understand you as having come to some substantive moral conclusion about this flower's moral character; instead, it would make far more sense to read your claim as communicating that we would commit a category mistake if we applied the term 'virtuous' to flowers. ${ }^{13}$ Consequently, even though it is extremely plausible to read claims such as $(\neg \mathrm{M})$ as moral, it seems that they need not necessarily be so interpreted.

If so, we might draw two lessons from this error-theoretic counterargument to relaxed readings of moral ontology. Firstly, when determining how to categorize statements such as $(\neg \mathrm{M})$, it would be far too quick to conclude that $(\neg \mathrm{M})$ is not moral because it does not ascribe any moral property, just as it would be far too quick to read $(\neg \mathrm{M})$ as a moral claim because it can be so interpreted. Instead, in line with relaxed philosophers' general approach, we need to determine in which context-i.e. within which domain and on which grounds- $-(\neg \mathrm{M})$ is defended and put forward.

Secondly, even if it were agreed that $(\neg \mathrm{M})$ can be used to convey different information and carry non-literal content, this would not necessarily disprove relaxed philosophers' take on moral ontology. Whether or not it would depends on which information is supposed to be communicated by the use of $(\neg \mathrm{M})$. After all, if $(\neg \mathrm{M})$ relays information which it does not 'wear on its sleeve', it should be possible to explicate this information by use of some other claim, the nature of which is then open to debate. For instance, imagine that when you utter $(\mathrm{M})$ and I utter $(\neg \mathrm{M})$, we should not be understood as disagreeing about the moral status that some specific moral theory ascribes to generating unhappiness (on this we agree), but about which moral theory correctly specifies the application conditions of 'wrong'. So let us say that by endorsing (M), you communicate something along the very rough lines of "Hedonists are right," whereas I use $(\neg \mathrm{M})$ to convey "Hedonists are wrong." Since these further, implicitly communicated claims are also moral, it is clear that we would not have left moral discourse even if $(\mathrm{M})$ and $(\neg \mathrm{M})$ were interpreted as expressing claims about the application conditions of 'wrong'. Consequently, referring to the possibility of non-literal uses of $(\neg M)$ does not settle the debate in error-theorists' favor, but simply expands it to the status of the claims that are implicitly conveyed. And if these tacitly communicated claims concerned once more error-theorists' traditional theses, we would be back to square one: relaxed philosophers will object that these error-theoretic claims are either misguided or domain-internal.

Consequently, this recent error-theoretic attempt to establish non-moral categorizations of claims such as $(\neg \mathrm{M})$ and "There are no moral truths" is not sufficient to rebut relaxed readings of moral ontology. However, these last remarks on metalinguistic uses of $(\neg \mathrm{M})$ might still point error-theorists in the right direction. For, if errortheorists could shift focus from metaphysical concerns about the property of wrongness to metasemantic enquiries into moral concepts such as 'wrongness', new avenues might indeed open up, although error-theorists would have to be careful about how to develop them. One way of doing so will be presented next.

13 Some relaxed realists, such possibly as Kramer (2009), might point out that identification of category mistakes also relies on moral considerations, in that it is they which show why flowers are no suitable objects for moral assessment. I prefer reading category mistakes in conceptual terms, in that someone who sincerely applies terms such as 'virtuous' to flowers is not a competent user of moral language. 


\section{From Metaphysics to Metasemantics}

I have briefly mentioned above that error-theories generally comprise a conceptual component-for instance, proclaiming that moral discourse is committed to the existence of irreducibly normative favoring relations - and an ontological claim-in this case, that no such irreducibly normative favoring relations exist. In addition, I have not so much argued as stated that according to relaxed philosophers, error-theorists' ontological thesis is either misguided if based on domain-external, metaphysical criteria which are wrongly applied to moral ontological commitment, or must be re-interpreted as a form of internal skepticism. Assume that relaxed philosophers are right: whether or not there are moral truths is a moral question. Is there some way in which errortheories could still be understood as a form of external skepticism?

If we want to give a positive answer, the way forward seems to be clear: if errortheories' ontological component is not suited to establish external status, moral ontology should be left behind and conceptual matters should move to the fore. Indeed, this step should not feel unusual to error-theorists. To start with, not all error-theories are (purely) metaphysically driven: identifying some thesis that is central to a discourse, say about irreducible normativity, and then arguing that this thesis is false because irreducibly normative reasons would be metaphysically queer, is one way to develop an errortheory, but not the only way. Rather, error-theories can also be built on considerations of incoherence, propounding that moral thinking is flawed because it involves built-in contradictions. This is how Michael Smith (2010) interprets Mackie's claim that conceiving of moral truths as both objective and prescriptive is incoherent; arguably, it is also how Streumer's (forthcoming: \$30) argument, suggesting that moral properties would have to be both identical and non-identical to descriptive properties, could at least in part be understood. ${ }^{14}$ Focusing on such conceptual matters is, therefore, certainly not new to error-theorists, although relaxing about moral ontology will restrict how exactly this shift towards conceptual considerations can be fleshed out.

Nor is it new to modify our understanding of metaethical accounts in the wake of non-metaphysical accounts of semantic vocabulary such as truth, fact and representation. Most instructively, take the case of expressivism as an example: loosely put, preminimalism expressivism has traditionally been understood as a combination of the positive thesis that the meaning of moral claims is to be explained by appeal to the conative mental states expressed, and the negative thesis that there are no moral truths and facts. Given minimalist understandings of truth and fact, though, expressivists no longer want to deny that moral truths and facts exist. Post-minimalism conceptions of expressivism have thus undergone two developments. Firstly, their negative thesis has been dropped, so that expressivism is now characterized exclusively by its positive thesis about the meaning of moral vocabulary. Questions about the existence of moral truths and facts, in turn, are-fully in line with relaxed accounts of moral ontologyunderstood as domain-internal, moral queries. Hence, whilst expressivists such as Simon Blackburn and Allan Gibbard endorse the existence of moral truths and facts as participants of moral discourse, this endorsement does not form part of their distinctive metaethical account. Secondly, expressivism is more and more understood not as a semantic theory which specifies the meaning of moral claims, but as a metasemantic theory, which considers by virtue of what it is that moral claims come to possess their respective conceptual content. This, in turn, is a question which expressivists answer

\footnotetext{
${ }^{14}$ However, in contrast to the inferentialist account to be developed shortly, Streumer's account does rely on important metaphysical considerations (cf. n. 20 below).
} 
without using any of the referring expressions from moral discourse. Consequently, given this new, exclusive focus on their positive metasemantic thesis, neither minimalism about truth and fact nor relaxing about moral ontology undermine expressivism's status as a distinctive domain-external, metaethical theory.

Hence, if error-theorists could take a page out of expressivists' book and adapt this expressivist strategy to their own cause, they should stand a good chance of securing external status for their own position, too. If so, they need to provide, firstly, a distinctive metasemantic account of moral language which, secondly, secures the errortheoretic spirit and, thirdly, does so without employing metaphysically driven arguments about moral truths and properties.

The inferentialist account that I will present next is certainly not the only way in which these criteria could be met. However, drawing on an inferentialist theory of meaning is, I believe, particularly well suited to do so. Accordingly, I will first give an extremely terse overview of those inferentialist elements which are relevant for my project; I will then reject an inferentialist suggestion as to how error-theories could be understood; finally, I will present how I believe inferentialist error-theories should be developed.

\subsection{Inferentialism, and How Not to Construe Error-Theories}

According to inferentialism's central metasemantic thesis, statements possess their specific conceptual content by virtue of the inferential role which they assume within the practice of making statements and asking for reasons (Brandom 1994). This inferential role includes the fact that statements can license as well as be licensed by other claims; that is, they can function as premises as well as conclusions of material inferences. At the same time, these claims are not only marked by their inferential relations to other claims, but also by non-inferential relations to certain non-linguistic phenomena outside the language game. On the one hand, these concern perceptions and observations which are non-inferentially linked to observation reports such as "This cup is red," and thus provide input to the language game through so-called language entry transitions. On the other hand, these non-linguistic phenomena pertain to actions, which are noninferentially related to practical commitments such as "I shall spend the day with my nephews," and can thus be understood as output of the language game that follow from language exit transitions (Brandom 1994: 234-235). Those claims which are partially characterized by language entry transitions, we can call doxastic or theoretical; those which are partially characterized by language exit transitions, we can call practical. Finally, different vocabularies are associated with different functions, in that they allow us to do different things within the game of giving and asking for reasons. For instance, observation reports such as "The sun shines today" enable language entry transitions by reporting our reliable discriminative reactions to our environment (Williams 2013). Other vocabularies have a very different, expressive function in that they allow us to render inferential roles explicit which would otherwise remain implicit. Take logical vocabulary as an example: although it is implicit in our inferential practices that the commitment "Humphrey is a dog" licenses and requires the commitment "Humphrey is an animal," we cannot talk about this inferential relation unless we are in possession of logical vocabulary that explicates this inference by stating "If Humphrey is a dog, then he is an animal." Inferentialists are, therefore, pragmatists: in order to grasp the significance of different vocabularies, we need to understand what they allow us to do when using them. 
Hence, if inferentialism is to help us develop a new perspective on metaethics, we need to understand metaethical accounts as carving out distinctive, competing theses about moral vocabulary within this inferentialist framework. Matthew Chrisman (2008: 353), who is arguably the most vocal supporter of inferentialist metaethics, suggests the following characterizations ${ }^{15}$ :

Inferentialist Expressivism: Moral claims express practical commitments.

Inferentialist Moral Realism: Moral claims express theoretical commitments and some of them are true.

Inferentialist Error-Theories: Moral claims express theoretical commitments and none of them is true.

One advantage of these inferentialist metaethical understandings is the close proximity to their traditional counterparts: inferentialist error-theories differ from inferentialist expressivists in that they agree with inferentialist moral realists on how the meaning of moral vocabulary is to be explained, yet disagree with inferentialist moral realists about the existence of moral truths. As such, this proposal preserves the orthodox view that error-theorists and moral realists both concur that moral claims are purportedly representational and that moral content is to be explained representationally, whilst only the latter additionally believe that these claims represent successfully, i.e. that some of them are true. However, as should be evident from the explanations given above, this seeming advantage turns out to be a significant disadvantage if relaxed moral ontology is presupposed as the background of our discussion. For, if the existence of moral truths and successful representation continued to shoulder the burden of demarcating moral realism from error-theories within this inferentialist framework, we would just find ourselves back with the relaxed philosophers' thesis that questions of successful representation are to be settled on moral grounds. If successful representation constituted the sole bone of contention between inferentialist error-theorists and moral realists, therefore, they would disagree on domain-internal grounds only, but would be metaethically indistinguishable with regard to their metasemantic account of moral content. Consequently, this first inferentialist take establishes error-theories neither as a distinctive metaethical position, nor as a form of external skepticism, and thus fails to advance the debate.

Accordingly, if inferentialism is supposed to help secure error-theories' external status, we need a more radical departure from traditional metaethical understandings than this first inferentialist suggestion can provide. This means that inferentialist errortheories must differ from moral realism not with regard to moral existential theses, but in relation to their metasemantic account of moral vocabulary. And this implies that in order to carve out a distinctive domain-external position, error-theorists need to present metasemantic theses which, firstly, differ both from realist and expressivist suggestions, secondly, capture the core error-theoretic thesis that something is amiss in moral discourse and, thirdly, do so without falling back on metaphysical assumptions about moral ontology.

15 This is a slight modification of Chrisman's (2008) proposal, in that Chrisman considers ethical statements and offers a slightly different account of theoretical and practical commitment. In a later paper, Chrisman (2011) proposes a suggestion based on explanatory considerations. For more details, see my (2016). 


\subsection{Inferentialist Error-Theory as External Skepticism}

When tackling this task, it is helpful to start once more with error-theorists' metaethical competitors. To bring out expressivists' and moral realists' metasemantic theses more clearly, let us furthermore follow recent suggestions within the creeping minimalism debate that associate expressivism with non-representationalism, and moral realism with representationalism. Transposed into an inferentialist key, this means that both moral realists and expressivists agree that meaning is explained by inferential role, yet disagree on what the inferential role of moral vocabulary consists in:

Non-Representationalism: Moral vocabulary is expressive.

Representationalism: Moral vocabulary is non-expressive.

According to inferentialist expressivists, moral vocabulary falls into the same category as the logical terms mentioned above: it makes inferential relations explicit which would otherwise remain implicit (Brandom 1994). At the same time, it differs from other expressive vocabularies such as logical terms, in that it makes specific inferences explicit. These are practical inferences, which have doxastic commitments as their premises and practical commitments as their conclusions. ${ }^{16}$ To elaborate, when examining the intricate web of inferential relations together with non-inferential language exit and entry transitions, inferentialist expressivists explain that we can observe that inferences from doxastic statements, such as "Visiting one's grandmother makes her happy," to practical commitments, such as "I shall visit my grandmother," are generally endorsed as materially good inferences. Moreover, we can observe that we are clearly able to act on the basis of these practical commitments, namely by visiting our grandmothers more often. However, expressivists will stress that what we cannot do is talk about these inferential relations, unless we possess special terms to do so. These terms, inferentialist expressivists now tell us, are moral concepts: it is they which allow us to formulate statements such as "Visiting one's grandmother is good," and thus to put into language and speak about what already exists in our practices but has so far remained implicit. Obviously, this expressivist suggestion requires further clarification and could be spelt out in different ways. However, its core idea should be clear: moral vocabulary explicates practical inferences. Consequently, if there were no such inferences to be explicated, inferentialist expressivists conclude, we would not speak in moral terms.

Adopting a representationalist stance, inferentialist moral realists disagree: moral vocabulary is not expressive. As such, they submit that inferentialist expressivists wrongly describe our practices when claiming that moral vocabulary explicates what is already an implicit component of the inferentialist web. For, when we look at the vast mesh of inferences, we can observe that inferences from statements such as "Visiting one's grandmother makes her happy" to "I shall visit my grandmother" are not generally regarded as sound, unless it is also thought that we are entitled to the claim "Visiting one's grandmother is good because it makes her happy." If we take away this premise, entitlement to the inference is generally held to collapse. Hence, a statement such as "Visiting one's grandmother is good" does not explicate an already existing sound inference, but provides a premise without which no sound inference would exist. Hence, moral vocabulary is not expressive, or so inferentialist moral realists conclude. Instead,

\footnotetext{
${ }^{16}$ For simplicity's sake, I follow Brandom (1994) here. For an alternative inferentialist account, see Chrisman (2016).
} 
it is characterized by its link to language entry transitions: rather than making explicit what is already there, it provides new input to the language game.

Again, much more would need to be said to flesh out exactly what this inferentialist construal of representationalism involves. ${ }^{17}$ However, what these very rough overviews have hopefully shown is that inferentialist expressivists and moral realists offer very different accounts of moral vocabulary, with the former linking it to expressive functions and the latter associating it with language-entry transitions. At the same time, I have argued that in order to secure external status and qualify as a distinctive metaethical account, inferentialist error-theorists must depart from traditional errortheorists more radically by rejecting not just expressivists' non-representationalism, but also moral realists' representationalism: if they kept concurring with moral realists that moral claims are purportedly representational and disagreed only with regard to successful representation, their disagreement would be domain-internal, not external. But if inferentialist error-theorists are barred from adopting representationalism and nonrepresentationalism, what is there possibly left for them to argue? Well, they could claim that both inferential moral realists and expressivists are mistaken in thinking that the inferential role of moral vocabulary can be coherently specified in the first place. More precisely, they could hold that:

Inferentialist Error-Theories*: The inferential role of moral claims is incoherent.

What could this incoherence comprise? Obviously, it will be up to inferentialist errortheorists to fill in the details. Still, Michael Williams's (2013) suggestion of explaining vocabularies on grounds of so-called 'EMUs'-explanations of meaning in terms of use-may give us a hint as to how error-theorists might proceed.

EMUs comprise three different components:

(I) A material-inferential (intra-linguistic) component, specifying the inferential patterns in which a concept $C$ stands.

(E) An epistemological component, detailing epistemological demands imposed on $C$-claims.

(F) A functional component, determining $C$ s function.

(I) and (E) capture how certain terms are used, and thus arguably specify their conceptual content; (F) makes explicit what they are used for. Accordingly, error-theorists could establish incoherence in at least two different ways. Firstly, they could argue that it is impossible to provide coherent (I)- and (E)-clauses of moral vocabulary. For instance, they could seek to establish that when engaging in moral discourse, we necessarily enter

17 This is by no means an easy feat. One possible suggestion, which has recently gained some currency, suggests that this inferentialist form of representationalism may involve explaining moral vocabulary on the basis of our discriminative reactions to our moral environment, or maybe on grounds of certain explanatory theses (Chrisman 2011). Partly for the reasons mentioned below, I believe that it is extremely difficult - if not impossible! — for relaxed realists to be representationalists. Hence, it might well be the case that moral realists face a choice: either endorse representationalism and accept a robust form of realism, or relax about moral truths and defend non-representationalism. 
commitments which are central to moral discourse but contradictory, in that entering one of these commitments is held necessarily to preclude entitlement to another. For instance, take moral discourse and the skepticism some error-theorists harbor about categorical normativity. Translated into inferentialist terminology, error-theorists could proffer the thesis that moral discourse commits us to the following triad of incompatible claims:

(1) Moral commitments are practical commitments.

(2) Practical commitments are treated as carrying entitlement iff they form the conclusion of a practical inference which is entitlement-preserving for a specific interlocutor on grounds of her particular preferences or social status.

(3) Moral commitments are treated as carrying entitlement iff they form the conclusion of a practical inference which is entitlement-preserving for any interlocutor, irrespective of her preferences or social status.

This suggestion should sound familiar: it emulates Joyce's (2001) error-theoretic argument. Hence, if inferentialist error-theorists could convincingly argue that we are indeed centrally committed to all three claims, there would be no coherent way for us to engage in moral discourse: commitment to any two of these claims necessarily precludes entitlement to the remaining third. As such, no consistent (I)- and (E)-clauses of moral vocabulary would be possible.

The second way to spell out incoherence departs from such better-known errortheoretic approaches by not targeting (I) and (E), but (F). As such, it does not point out allegedly inconsistent positions to which we commit ourselves within the language game, but questions the possibility to provide a coherent account of moral vocabulary's very function. Above, we have encountered two competing accounts of moral vocabulary's (F)-clause: inferentialist moral realists maintain that moral terms are used for language-entry moves, whereas inferentialist expressivists hold that they are used to make implicit practical inferences explicit. Inferentialist error-theorists could now submit that both are wrong: neither realists' nor expressivists' proposed (F)-clause is tenable. Let us begin with realists' representationalism, and thus the claim that moral vocabulary facilitates language-entry transitions by allowing us to adopt positions within the languagegame in response to our environment. How could error-theorists attack this account? They could start by pointing out that the paradigmatic example for language-entry transitions concerns observation reports such as "This cup is red": employing the term 'red' enables us to express the reactions we have when seeing things that are red. As this shows, though, language-entry transitions are crucially to do with perception and observation, and thus causation. ${ }^{18}$ However, when relaxing about moral ontology, relaxed philosophers themselves have argued that causal considerations are inappropriate within the moral context: to think otherwise, they have explained, is to misapply requirements that are adequate within the natural domain to the moral domain. Accordingly, taking relaxed philosophers at their word, inferentialist error-theorists could smartly highlight that if relaxed philosophers are right in claiming that causal considerations do not apply within the moral domain, and if the language-entry transitions featuring in moral realists' suggested (F)-clause presuppose causal relations, then their own relaxed stance on moral ontology precludes the representationalist $(\mathrm{F})$-clause that moral realists suggest

\footnotetext{
${ }^{18}$ Indeed, according to inferentialists, it is this that bestows empirical content to observation reports (Brandom 1994: 234).
} 
within their metasemantic account: without causal relations, moral vocabulary cannot facilitate language-entry transitions. ${ }^{19}$ This leaves expressivists' non-representationalism, holding moral vocabulary to explicate what is already implicit in our inferential practices. Yet, with regard to this functionalist thesis, inferentialist error-theorists can appropriate realists' criticism of expressivism by agreeing that it simply is not the case that we endorse certain inferences as good and then merely explicate these moves by using moral claims. On this, inferentialist realists are right: moral premises do not make inferences explicit, they make them sound. Hence, if it were the case that making others happy is good, we could indeed license our practical commitment to visit our grandmothers on grounds of the doxastic commitment that doing so would make them happy; otherwise, this doxastic commitment would confer no such entitlement to the practical commitment. Consequently, although some vocabularies may be expressive, inferentialist error-theorists could conclude that moral vocabulary is not one of them. If so, moral vocabulary can neither be understood on the basis of language-entry transitions, as inferentialist moral realists would claim, nor on grounds of expressive functions, as inferentialist expressivists would have it. As such, the function of moral vocabulary remains obscure: there is no $(\mathrm{F})$-clause that could coherently specify it.

Of course, I do not mean to suggest here that either of these error-theoretic strands of thought is sufficiently spelt out. Nor do I want to claim that either argument is successful: as I said at the outset, I am not an error-theorist. However, if they could be made to work, we would have found a coherent form of external skepticism: Firstly, this second take on inferentialist error-theories differs both from realist and expressivist accounts of moral language and assumes, therefore, a distinctive position on a domainexternal, metasemantic question. Secondly, it captures the characteristic error-theoretic thrust that moral discourse is fundamentally flawed, in that we cannot provide a coherent account of moral vocabulary. Hence, whereas non-inferentialist error-theorists may have claimed that the idea of moral properties is incoherent in that such properties would have to be both objective and prescriptive, inferentialist error-theorists maintain that moral vocabulary is defective since no consistent account of its inferentialist role is available. As a by-product, this revised understanding of inferentialist error-theories thus also attacks a crucial premise of the relaxed approach to moral ontology, namely that moral discourse is a well-disciplined domain that is governed by coherent standards, which provide the grounds on which the truth-values of moral existential claims are assessed. By adopting the inferentialist approach suggested here, error-theorists argue that this is false: the moral domain cannot be coherently reconstructed. Thirdly, it establishes as much on the basis of inquiries into the conceptual role of moral concepts, and thus without drawing on metaphysical, domain-external considerations about moral ontology: linking moral vocabulary with language-entry transitions has not been ruled out on grounds of alleged metaphysical queerness, say, but by appeal to relaxed philosophers' own take on moral ontology. ${ }^{20}$ Nor have metaphysical considerations featured when rejecting moral terms' allegedly expressive function.

19 Do relaxed moral realists have to provide a metasemantic account of moral language? As he has indicated in personal conversation, Scanlon does not appear to think so. However, I believe that this position is not tenable. Without arguing this point here, I hold that relaxed moral realists need to draw on metasemantic theses to deal with several challenges to their position, such as those to do with domain-individuation and ontological proliferation.

20 Arguably, in this respect it differs from Streumer's (forthcoming: ch. 2) incoherence argument, which is partly based on metaphysical considerations about property-identity. 
Consequently, this specific inferentialist understanding of error-theories neither proffers a form of representationalism, nor is defined by negative theses on successful representation. As such, it emulates expressivists' strategy by characterizing the errortheoretic position in purely metasemantic, non-ontological terms. However, in contrast to expressivists, who combine their distinctive metasemantic account of moral vocabulary with the domain-internal endorsement of moral truths and facts, inferentialist error-theorists eschew all claims on moral ontology. Relaxed moral ontology and nonmetaphysical, minimalist conceptions of truth and fact can, therefore, pose no threat to the distinctive, external status of error-theories. Consequently, the suggested inferentialist understanding of error-theories puts error-theorists back on the metaethical map without any risk of drawing them back within the moral domain.

\section{Inferentialist Error-Theories: Gains and Losses}

How happy should error-theorists be about this inferentialist turn? Admittedly, this is not quite clear. For, whilst this inferentialist proposal comes with certain advantages, it also incurs non-negligible costs.

Starting with its advantages, most importantly for our purposes, this inferentialist construal secures error-theories' status as a distinctive form of external skepticism even if it were granted to relaxed philosophers that moral ontology is itself moral. Moreover, despite no longer mentioning moral truths and properties, nor successful or purported representation-indeed, despite not even using moral vocabulary - this characterization aims to retain the spirit, albeit not the letter, of error-theories by showing that moral discourse is fundamentally flawed. Finally, by eschewing all theses about moral truths, this re-construal of error-theories also delivers the positive side-effect that error-theorists no longer need to worry about the charge that their position cannot be consistently formulated. That is, whereas incoherence loomed with regard to traditional definitions in terms of the non-existence of moral truths, which lead either to errortheoretic theses' being limited to positive moral propositions only or to the thoughts on implicatures briefly discussed above, no such problems arise with regard to the suggested inferentialist understanding.

Turning to its costs, though, it is clear that although this inferentialist characterization seeks to be true to error-theories' spirit, it cannot capture it entirely. After all, error-theories' distinctive claim has traditionally been that although moral assertions purport to represent moral reality, they fail to do so because there is simply nothing to represent. This was, after all, what was supposed to distinguish error-theories both from moral realism and expressivism. The suggested inferentialist construal leaves no space for this claim, although it does retain error-theorists' thesis that moral discourse is in some way defective. Whether or not this manages to preserve enough of the errortheoretic spirit, is only for error-theorists to decide. For those who do not want to content themselves with this clipped error-theoretic construal, yet want to save errortheories as a form of external skepticism, the task seems clear: either they must present an alternative to this inferentialist suggestion which can achieve everything that the inferentialist proposal manages to do and retain more of the error-theoretic spirit; or they must reject relaxed, moral readings of moral ontology. 


\section{References}

Blackburn, S. 1998. Ruling Passions. A Theory of Practical Reasoning. Oxford: Clarendon Press.

Brandom, R. 1994. Making it Explicit: Reasoning, Representing, and Discursive Commitment. Cambridge, MA: Harvard University Press.

Carnap, R. 1950. "Empiricism, Semantics, and Ontology," Revue Internationale de Philosophie 4: 20-40.

Chrisman, M. 2008. "Expressivism, Inferentialism, and Saving the Debate', Philosophy and Phenomenological Research 77, pp. 334-358.

2011. "Expressivism, Inferentialism and the Theory of Meaning." In M. Brady (ed.), New Waves in Metaethics, 103-125. London: Palgrave Macmillan.

- 2016. The Meaning of 'Ought': Beyond Descriptivism and Expressivism in Metaethics. New York: Oxford University Press.

Dreier, J. 2004. "Metaethics and the Problem of Creeping Minimalism," Philosophical Perspectives 18: 23-44.

Dworkin, R. 1996. "Objectivity and Truth: You'd Better Believe It," Philosophy and Public Affairs 25: 87-139.

- 2011. Justice for Hedgehogs. Cambridge, MA: Belknap Press.

Horgan, T. and M. Timmons 2015. "Modest Quasi-Realism and the Problem of Deep Moral Error." In R. Johnson and M. Smith (eds.), Passions And Projections: Themes From The Philosophy Of Simon Blackburn, 190-209. Oxford: Oxford University Press.

Joyce, R. 2001. The Myth of Morality. Cambridge: Cambridge University Press.

Kramer, M. 2009. Moral Realism as a Moral Doctrine. Chichester: Wiley-Blackwell.

Mackie, J. 1977. Ethics: Inventing Right and Wrong. London: Penguin.

Nagel, T. 1986. The View from Nowhere. Oxford: Oxford University Press.

Olson, J. 2014. Moral Error Theory: History, Critique, Defence. Oxford: Oxford University Press.

Pigden, C. 2007. "Nihilism, Nietzsche and the Doppelganger Problem," Ethical Theory and Moral Practice 10: 441-456.

Parfit, D. 2011. On What Matters: Volume Two. Oxford: Oxford University Press.

Scanlon, T. 2014. Being Realistic about Reasons. Oxford: Oxford University Press.

Sinnott-Armstrong, W. 2006. Moral Skepticisms. Oxford: Oxford University Press.

Smith, M. 2010. "Dworkin on External Skepticism," Boston Law Review 90: 509-520.

Streumer, B. Forthcoming. Unbelievable Errors. Oxford: Oxford University Press.

Thomasson, A. 2007. Ordinary Objects. Oxford: Oxford University Press.

Tiefensee, C. 2016. "Inferentialist Metaethics, Bifurcations and Ontological Commitment," Philosophical Studies 173: 2437-2459.

Williams, M. 2013. "How Pragmatists Can Be Local Expressivists." In H. Price, with S. Blackburn, R. Brandom, P. Horwich, and M. Williams, Expressivism, Pragmatism and Representationalism, 128-144. Cambridge: Cambridge University Press. 